\title{
Correlation between heats of immersion and limiting capacitances in
}

\section{porous carbons}

\author{
T.A. Centeno ${ }^{a}$, J.A. Fernandez ${ }^{a}$ and F. Stoeckli ${ }^{b^{*}}$ \\ a Instituto Nacional del Carbón-C.S.I.C. Apartado 73, 33080 Oviedo, Spain \\ ${ }^{b}$ IMT-Chimie des Surfaces, Université de Neuchâtel, rue Emile Argand 11, CH- \\ 2009 Neuchâtel, Switzerland
}

\section{Abstract}

Based on more than 80 carbons, the paper shows that immersion calorimetry into benzene, water and carbon tetrachloride can be used to assess with a good accuracy the limiting capacitance $\mathrm{C}_{\mathrm{o}}$ at low current densities in both acidic $(2 \mathrm{M}$ $\mathrm{H}_{2} \mathrm{SO}_{4}$ ) and aprotic (1M tetraethyl ammonium tetrafluoroborate in acetonitrile) electrolytic solutions. The enthalpies of immersion $\Delta_{\mathrm{i}} \mathrm{H}\left(\mathrm{C}_{6} \mathrm{H}_{6}\right)$ and $\Delta_{\mathrm{i}} \mathrm{H}\left(\mathrm{H}_{2} \mathrm{O}\right)$ provide information on $\mathrm{C}_{\text {o-acidic }}$, where both the surface area and the oxygen content play a role. On the other hand, in the case of the organic electrolyte the oxygen content has only a small influence and $\mathrm{C}_{\mathrm{o} \text {-aprotic }}$ is directly related to $\Delta_{\mathrm{i}} \mathrm{H}\left(\mathrm{C}_{6} \mathrm{H}_{6}\right)$ and $\Delta_{\mathrm{i}} \mathrm{H}\left(\mathrm{CCl}_{4}\right)$. Carbon tetrachloride has a critical dimension (0.65 $\mathrm{nm})$, which is close to the size of the $\left(\mathrm{C}_{2} \mathrm{H}_{5}\right)_{4} \mathrm{~N}^{+}$ion $(0.68 \mathrm{~nm})$ and therefore $\Delta_{\mathrm{i}} \mathrm{H}\left(\mathrm{CCl}_{4}\right)$ provides better information in the case of carbons with small micropores. The advantage of this approach lies in the fact that immersion

\footnotetext{
* Corresponding author. Tel.: +41 327182425; Fax: +41 327182511.

E-mail address: fritz.stoeckli@unine.ch (F. Stoeckli)
} 
calorimetry, in itself a useful tool for the structural and the chemical characterization of carbons, can also be used to evaluate directly the gravimetric capacitances of these solids at low current densities.

\section{Introduction}

Porous carbons have applications in electrochemical capacitors and they are the subject of active research, in order to identify the best potential candidates and to improve their performances. Obviously, electrochemical experiments can be performed directly in order to determine the fundamental EDLC properties, but a basic knowledge of the material is required in any case. As shown elsewhere [1-4], the structural and chemical characterization requires, as a minimum, the determination of an adsorption isotherm, for example $\mathrm{N}_{2}$ at $77 \mathrm{~K}$. The latter provides information on the porosity and on the total surface area with the help of a comparison plot based on a non-porous reference [5]. More information can be gained from immersion calorimetry into liquids of molecular dimensions between 0.4 and $1.5 \mathrm{~nm}$. It is a powerful tool for a refined characterization of porous carbons and provides information on the accessibility of the micropore system. Furthermore, immersion into water provides information on the oxygen content of the surface $[2,3,6]$. Since the accessible surface area of the carbon and its oxygen content play a role in the specific capacitance, it is logical to correlate them with the information provided by immersion calorimetry and adsorption isotherms. The present study develops the approach outlined earlier [7-11] and shows that a good assessment of the 
gravimetric capacitance at low current densities can be achieved on the basis of immersion calorimetry. Both properties, given respectively in $\mathrm{F} \mathrm{g}^{-1}$ and $\mathrm{J} \mathrm{g}^{-1}$, are related to the unit weight of carbon as opposed to other studies more oriented towards the study of surface related capacitances, such as Chmiola et al.[12,13]

\section{Theoretical background}

\subsection{Electrochemistry}

It has been shown recently $[6,8]$ that the limiting capacitance $C_{0}$ at low current density $\mathrm{j}$ (typically $1 \mathrm{~mA} \mathrm{~cm}^{-2}$ ) in acidic $\left(2 \mathrm{M} \mathrm{H}_{2} \mathrm{SO}_{4}\right)$ and aprotic $\left(\left(\mathrm{C}_{2} \mathrm{H}_{5}\right)_{4} \mathrm{NBF}_{4}\right.$ in acetonitrile) electrolytes depends on the surface area $\mathrm{S}_{\text {tot }}$ accessible to the different ions and on the surface groups desorbed as $\mathrm{CO}$ in thermally programmed desorption (TPD). For a large number of carbons the following correlations have been obtained

$\mathrm{C}_{\text {o-acidic }}\left(\mathrm{Fg}^{-1}\right)=(0.081 \pm 0.007)\left(\mathrm{F} \mathrm{m}^{-2}\right) \mathrm{S}_{\text {tot }}\left(\mathrm{m}^{2} \mathrm{~g}^{-1}\right)+(63 \pm 5)\left(\mathrm{F} \mathrm{mmol}^{-1}\right)[\mathrm{CO}]\left(\mathrm{mmolg}^{-1}\right)(1)$

and

$\mathrm{C}_{\text {o-aprotic }}\left(\mathrm{Fg}^{-1}\right)=0.08\left(\mathrm{Fm}^{-2}\right) \mathrm{S}_{\mathrm{tot}}\left(\mathrm{m}^{2} \mathrm{~g}^{-1}\right)+9\left(\mathrm{Fmmol}^{-1}\right)[\mathrm{CO}]\left(\mathrm{mmol} \mathrm{g}^{-1}\right)$

The latter expression applies to carbons with average micropore widths $L_{\circ}>$

$0.75-0.80 \mathrm{~nm}$ and it is found that the ratio $C_{0-\text { aprotic }} / \mathrm{C}_{\text {o-acidic }}$ is approximately 0.54 $\pm 0.09[9]$. 
In the case of the aprotic electrolyte, the contribution from the CO-generating groups to $C_{o}$ (a pseudo-capacitance effect) is small, even for chemically treated carbons (for untreated carbons, [CO] does not exceed 1-2 $\mathrm{mmol} \mathrm{g}^{-1}$ ).

It has also been shown that a higher current densities $C[j]]_{a c i d i c}$ depends on $L_{\circ}$ $(\mathrm{nm})$, the average width of the locally slit-shaped micropores and on the surface groups generating $\mathrm{CO}_{2}$ in TPD [7],

$\mathrm{C}[]]_{\text {acidic }}\left(\mathrm{F} \mathrm{g}^{-1}\right)=\mathrm{C}_{\text {o-acidic }} \exp \left[-j\left(0.0018 / \mathrm{L}_{\circ}+0.0060\left[\mathrm{CO}_{2}\right]\right)\right]$

where $\left[\mathrm{CO}_{2}\right]$ is given in $\mathrm{mmol} \mathrm{g}^{-1}$.

Since the ratio of $\left[\mathrm{CO}_{2}\right]$ to the total amount of oxygen $[\mathrm{O}]$ is relatively constant for a variety of activated carbons [7, 14-17], Eq. (3) can be replaced with a very good approximation by

$C[]_{\text {acidic }}\left(\mathrm{F} \mathrm{g}^{-1}\right)=\mathrm{C}_{\mathrm{o}-\text { acidic }} \exp \left[-j\left(0.0018 / \mathrm{L}_{o}+0.0013[\mathrm{O}]\right)\right]$

Centeno et al. [9] have shown that for carbons with $\mathrm{L}_{\circ}>0.75-0.80 \mathrm{~nm}$ the ratio $\mathrm{C}[\mathrm{j}]_{\text {aprotid }} / \mathrm{C}[\mathrm{j}]_{\text {acidic }}$ is almost constant in the range of 1 to $50-70 \mathrm{~mA} \mathrm{~cm}{ }^{-2}$. This means that Eqs. (3)-(4) also apply to the decrease of $C_{\text {aprotic }}$ with $j$, with the same exponential part.

It follows that for typical microporous and mesoporous carbons reliable predictions can be made on the basis of the total surface area and the surface groups generating $\mathrm{CO}$ and $\mathrm{CO}_{2}$ in TPD. The latter species corresponds, with a good approximation, to the acidic groups determined by $\mathrm{NaOH}$ titration and 
$\left[\mathrm{CO}_{2}\right]$ can be replaced in Eq. (3) by the number of meq $\mathrm{NaOH}$ per gram of carbon.

\subsection{Characterization by adsorption isotherms and immersion calorimetry}

The foregoing section shows that the surface area of the carbon is an essential parameter in the EDLC properties and therefore its correct determination is of prime importance. As discussed elsewhere $[3,4,8]$, the socalled BET surface area is often unreliable in the case of microporous carbons, where it reflects the monolayer equivalent to the volume filling the locally slitshaped pores. Therefore, $\mathrm{S}_{\mathrm{BET}}$ can be misleading when it is used to calculate surface-related properties such as capacitances in $\mathrm{F} \mathrm{m}^{-2}$ or functional group densities of microporous carbons.

It has been shown $[1,2$,$] that a reliable characterization of porous carbons$ can be obtained from the analysis of the adsorption isotherm over a wide temperature range using Dubinin's theory for the volume filling of micropores. This approach provides information on the volume $\mathrm{W}_{\mathrm{o}}$ of the ideally slit-shaped micropores, their average width $L_{\circ}$ and consequently on the surface area of their walls, $S_{m i}$. The latter is given by the simple geometrical relation $S_{m i}\left(m^{2} g^{-}\right.$ $\left.{ }^{1}\right)=2000 \mathrm{~W}_{\mathrm{o}}\left(\mathrm{cm}^{3} \mathrm{~g}^{-1}\right) / \mathrm{L}_{\mathrm{o}}(\mathrm{nm})$. As shown by Kaneko and others $[4,5]$, it can be cross-checked by the comparison of the nitrogen adsorption isotherm at $77 \mathrm{~K}$ on the given sample with the data for a non-porous reference carbon. The comparison plot provides information on both the total surface area and on the external (non microporous) area $S_{e}$ of the carbon. The total surface area of the 
carbon $S_{\text {tot }}=S_{m i}+S_{e}$ obtained from Dubinin's theory and from the comparison plot is in good agreement with the specific adsorption of phenol and caffeine from aqueous solutions [2, 18-20]. Due to their relatively low solubility in water, these molecules form exclusively monolayers on the carbon surface and their extent can be determined directly by immersion calorimetry. The conversion factors are respectively $-0.110 \mathrm{~J} \mathrm{~m}^{-2}$ and $-0.113 \mathrm{~J} \mathrm{~m}^{-2}$.

Excellent correlations have been reported for the total surface area $S_{\text {tot }}$ obtained from the different techniques $[7,8,11,21]$ and they confirm the unreliable nature of the BET surface area in the case of microporous carbons. At this stage it must be emphasized that the surface areas determined with by nitrogen, benzene and phenol adsorption include micropores of widths as low as $0.4 \mathrm{~nm}$, which are accessible to water and to the ions of acid and basic electrolytes (e.g. $\mathrm{H}_{2} \mathrm{SO}_{4}$ and $\mathrm{KOH}$ ). On the other hand, in the case of aprotic electrolytes with larger ions such as $\left(\mathrm{C}_{2} \mathrm{H}_{5}\right)_{4} \mathrm{~N}^{+}(0.68 \mathrm{~nm}[13,22])$, the pore size distribution and the presence of constrictions (gate effects) may limit the access to the total surface area of the carbon.

Pore size distributions, and implicitly the corresponding surface areas can be obtained from the analysis of adsorption isotherms of a small molecule such as $\mathrm{N}_{2}$ at $77 \mathrm{~K}$ (the so-called DFT method) or $\mathrm{CO}_{2}$ at $273 \mathrm{~K}$ [23-25]. The latter may be more reliable, as it avoids the problem of activated diffusion. However, $\mathrm{CO}_{2}$ does not reveal the presence of 'gate effects', which can be detected by the enthalpies of immersion of the carbon into liquids with different molecular dimensions $(0.4$ to $1.5 \mathrm{~nm})$. If constrictions are present, the pore size distributions obtained from the two techniques do not agree. In this case, 
calorimetry leads to an effective pore-size distribution which reveals the exclusion of certain molecules from micropores compatible with their size. This means that the surface area associated with these pores is no longer available to larger molecules or ions. For example, the industrial carbon molecular sieve T-0 examined earlier [23]. As indicated by immersion calorimetry, the average micropore width of $0.71 \mathrm{~nm}$ given by $\mathrm{CO}_{2}$ modelling is shifted to $0.55 \mathrm{~nm}$ following the creation of constrictions (gate effect) at the entrance of many pores. The small acid electrolyte is not affected by these constrictions and it uses entire surface area of this carbon $\left(785 \mathrm{~m}^{2} \mathrm{~g}^{-1}\right)$, with a specific capacitance of $94 \mathrm{~F} \mathrm{~g}^{-1} / 785 \mathrm{~m}^{2} \mathrm{~g}^{-1}=0.120 \mathrm{~F} \mathrm{~m}^{-2}$. On the other hand, the aprotic ion is largely excluded from the micropore system and the capacitance $\mathrm{C}_{\text {o-aprotic }}$ is only $21 \mathrm{~F} \mathrm{~g}^{-1}$. On the basis of Eq. (2), this value suggests an accessible surface area around 200 to $230 \mathrm{~m}^{2} \mathrm{~g}^{-1}$. It is smaller than expected from the surface of pores wider than $0.65 \mathrm{~nm}$ based on the $\mathrm{CO}_{2}$ pore size distribution (350 to 400 $\left.\mathrm{m}^{2} \mathrm{~g}^{-1}\right)$.

The foregoing discussion suggests that in the case of the $\left(\mathrm{C}_{2} \mathrm{H}_{5}\right)_{4} \mathrm{~N}^{+}$ion, the enthalpy of immersion into carbon tetrachloride, $\Delta_{\mathrm{i}} \mathrm{H}\left(\mathrm{CCl}_{4}\right)$, may be a useful indicator for the accessibility of the micropore system, since the two species have similar dimensions (respectively 0.68 and $0.65 \mathrm{~nm}$ ). Results based on this hypothesis are presented in the following section.

As shown elsewhere [6], immersion calorimetry into benzene and water also provides information on the total oxygen content of the surface,

$[\mathrm{O}]\left(\mathrm{mmol} \mathrm{g}^{-1}\right)=\left(0.21 \cdot \Delta_{\mathrm{i}} \mathrm{H}\left(\mathrm{C}_{6} \mathrm{H}_{6}\right)-\Delta_{\mathrm{i}} \mathrm{H}\left(\mathrm{H}_{2} \mathrm{O}\right)\right) / 10$ 
It is in good agreement with the total amount of oxygen obtained from thermally programmed desorption (TPD) and provides therefore an estimate of the capacitance $\mathrm{C}$ with the current density j, as given by Eq. (4).

It is also possible to dose the total amount of surface acidity by immersion calorimetry, using a $2 \mathrm{M} \mathrm{NaOH}$ solution [26]. The acidic groups are the main contributors to the desorption of $\mathrm{CO}_{2}$ in TPD [27] and therefore the number of meq $\mathrm{NaOH}$ per gram of carbon can be substituted to $\left[\mathrm{CO}_{2}\right]$ in Eq. (3).

\section{Experimental}

\subsection{Structural and chemical characterizations}

These techniques, described in detail elsewhere [1-5, 18-20, 23-29], were applied to more than 80 porous and non porous carbons used in the present study. The comparison of the various approaches provides a reliable picture for porous and non porous carbons of different origins [3, 4, 7-11,21]. Typical results corresponding to well characterized carbons are shown in Table 1.

\subsection{Electrochemical characterizations}

The electrochemical measurements were carried out in a potentiostatgalvanostat Autolab-Ecochimie PGSTAT30. Sandwich-type capacitors were prepared with two carbon pellets ( $8 \mathrm{~mm}$ in diameter) separated by glassy 
fibrous paper and placed inside a Swagelok-cell. The electrodes (11-12 mg) were obtained by pressing a mixture of $75 \mathrm{wt} \%$ of carbon, $20 \mathrm{wt} \%$ of polyvinylidene fluoride and 5 wt\% of carbon black (Super $\mathrm{P}$ ). $2 \mathrm{M} \mathrm{H}_{2} \mathrm{SO}_{4}$ aqueous solution and $1 \mathrm{M}\left(\mathrm{C}_{2} \mathrm{H}_{5}\right)_{4} \mathrm{NBF}_{4}$ in acetonitrile were used as electrolytes.

The capacitance $\mathrm{C}_{0}$ was determined by galvanostatic charge-discharge voltage cycles from 0 to $0.8 \mathrm{~V}$ in the acidic electrolyte and between 0 and $2 \mathrm{~V}$ in the aprotic medium, at a current density of $1 \mathrm{~mA}$ per $\mathrm{cm}^{2}$ of electrode surface.

\section{Results and discussion}

As pointed out earlier [9, 28, 29], relatively good correlations can be found between the limiting capacitances $\mathrm{C}_{\mathrm{o} \text {-acidic }}$ and $\mathrm{C}_{\mathrm{o} \text {-aprotic }}$ of pure carbons and their enthalpies of immersion into benzene, $\Delta_{\mathrm{i}} \mathrm{H}\left(\mathrm{C}_{6} \mathrm{H}_{6}\right)$. In the last analysis, this is not too surprising, since the electric double layer capacitance $C_{0}$ and immersion calorimetry are both related to surface effects. However, as suggested by Eqs. (1)-(2), a fraction of the surface oxygen desorbed as CO in TPD also plays a role in $\mathrm{C}_{0}$, to which it contributes in the form of a pseudocapacitance. It follows that the picture can be refined by considering also the enthalpy of immersion into water $\Delta_{\mathrm{i}} \mathrm{H}\left(\mathrm{H}_{2} \mathrm{O}\right)$, since it is related to the oxygen content of the surface. Using both enthalpies of immersion should improve the correlation with $\mathrm{C}_{\mathrm{o}}$. This is true in particular for the acidic electrolyte, where the contribution from the COgenerating groups is relatively important.

As illustrated by Fig. 1, the study of 89 porous carbons of different origins and with various amounts of surface oxygen leads to the correlation 
$\mathrm{C}_{\text {o-acidic }}\left(\mathrm{F} \mathrm{g} \mathrm{g}^{-1}\right)=-(0.64 \pm 0.04) \Delta_{\mathrm{i}} \mathrm{H}\left(\mathrm{C}_{6} \mathrm{H}_{6}\right)-(0.93 \pm 0.09) \Delta_{\mathrm{i}} \mathrm{H}\left(\mathrm{H}_{2} \mathrm{O}\right)$

If one considers only the non-specific surface interactions, reflected by $\Delta_{\mathrm{i}} \mathrm{H}\left(\mathrm{C}_{6} \mathrm{H}_{6}\right)$ only, one obtains

$\mathrm{C}_{\text {o-acidic }}\left(\mathrm{F} \mathrm{g}^{-1}\right)=-(0.95 \pm 0.02) \Delta_{\mathrm{i}} \mathrm{H}\left(\mathrm{C}_{6} \mathrm{H}_{6}\right)$

The correlation coefficients of 0.903 and 0.811 confirm the better fit achieved by Eq. (6), in particular for carbons with oxygen contents above 2 to $3 \mathrm{mmol} \mathrm{g}^{-1}$. As indicated by Eq. (5), $\Delta_{i} H\left(\mathrm{H}_{2} \mathrm{O}\right)$ reflects the total oxygen content [O] of the surface, whereas only the CO-generating complexes contribute to $\mathrm{C}_{\mathrm{o}}$. This may introduce some uncertainty, but for the carbons of the present study the ratio between [CO] and the total amount of oxygen [O] is approximately 0.6. Variations of this ratio introduce relatively small changes in the overall correlation (6).

Eqs. (6)-(7) are useful tools to estimate the suitability of a carbon to be used as electrode in a supercapacitor with an acidic electrolyte, in the present case 2 $\mathrm{M} \mathrm{H}_{2} \mathrm{SO}_{4}$. For other small electrolytes (for example $\mathrm{KOH}$ ), the $\mathrm{C}_{0}$ values are slightly different $[8,11,21]$ and it is likely that similar correlations should apply.

In the case of the aprotic electrolyte, the situation is different. One observes a sharp reduction of the ratio $\mathrm{C}_{\text {o-aprotid }} \mathrm{C}_{\text {o-acidic }} \sim 0.5$ for carbons with either a high fraction of micropores below $0.7 \mathrm{~nm}$ or larger pores, or with constrictions leading to 'gate' effects. Under these circumstances the $\left(\mathrm{C}_{2} \mathrm{H}_{5}\right)_{4} \mathrm{~N}^{+}$ion will be 
partly excluded from the micropore system and the corresponding surface area. It follows that a reliable correlation between $\mathrm{C}_{\mathrm{o} \text {-aprotic }}$ and the enthalpies of immersion into benzene can only be found for carbons with a majority of pores above 0.75 to $0.80 \mathrm{~nm}$ (Fig. 2). For 72 carbons of fulfilling this requirement, one obtains

$C_{\text {o-aprotic }}\left(F g^{-1}\right)=-(0.57 \pm 0.01) \Delta_{i} H\left(C_{6} H_{6}\right)$

with a correlation coefficient of 0.919 .

Since the relative contribution of surface oxygen to $\mathrm{C}_{0 \text {-aprotic }}$ is much smaller than in the case of $\mathrm{C}_{\mathrm{o}-\text { acidic, }}$ it is not surprising that $\Delta_{\mathrm{i}} \mathrm{H}\left(\mathrm{H}_{2} \mathrm{O}\right)$ does not improve Eq. (8). One obtains

$\mathrm{C}_{\text {o-aprotic }}\left(\mathrm{F} \mathrm{g} \mathrm{g}^{-1}\right)=-(0.56 \pm 0.02) \Delta_{\mathrm{i}} \mathrm{H}\left(\mathrm{C}_{6} \mathrm{H}_{6}\right)-(0.047 \pm 0.056) \Delta_{\mathrm{i}} \mathrm{H}\left(\mathrm{H}_{2} \mathrm{O}\right)$

The prefactor of only $-(0.047 \pm 0.056) \mathrm{F} \mathrm{J}^{-1}$ and the same correlation coefficient (0.919) confirm the limited influence of oxygen-containing surface complexes. In the case of carbons containing a significant fraction of its porosity below 0.7 $\mathrm{nm}$ (see Table 2) the experimental values of $\mathrm{C}_{\mathrm{o} \text {-aprotic }}$ are smaller than predicted by Eq. (8). This corresponds to the scatter observed in Fig. 2 below the correlation suggested by benzene. The latter is a small and flat molecule probing pores of $0.4 \mathrm{~nm}$ and therefore overrating the surface area accessible to the aprotic ion $(0.68 \mathrm{~nm})$. Therefore, it is not surprising that the enthalpy of immersion into carbon tetrachloride $(0.65 \mathrm{~nm})$ provides a better overall 
agreement. For 31 carbons with average pore sizes $L_{o}$ between 0.5 and $10 \mathrm{~nm}$, including those of Table 2, one obtains (see Fig. 3)

$$
C_{\text {o-aprotic }}\left(F^{-1}\right)=-(0.63 \pm 0.02) \Delta_{\mathrm{i}} \mathrm{H}\left(\mathrm{CCl}_{4}\right)
$$

with a correlation coefficient of 0.932 . As shown in Table 2, in the case of 9 carbons with pore sizes below $0.75 \mathrm{~nm}$, Eq. (10) provides a much better agreement than Eq. (8). It is also interesting to note that in the limiting case of a high surface area graphite (HSAG-300) shown for comparison purposes in Table 2, Eqs. (8) and (10) both lead to excellent agreements with the experimental value of $\mathrm{C}_{\text {o-aprotic. }}$. This is due to the fact that the same surface area is accessible to both benzene and carbon tetrachloride and therefore to the acidic and aprotic ions.

\section{Conclusions}

The present study shows that

(a) The techniques used routinely for the structural characterization of carbons (isotherms and in particular immersion calorimetry into benzene, water and carbon tetrachloride) can also provide information to assess the potentiality of porous carbons in supercapacitors. This approach allows a simple preliminary selection of relatively unknown carbons, before subjecting them to detailed 
EDLC characterizations. In view of its simplicity and the short time required for an experiment, the calorimetric technique can also be use for a preliminary assessment and for quality control, as it is already the case for applications in filtration technology.

(b) Eqs. (6) and (7) can be used for the prediction of the gravimetric capacitance $\mathrm{C}_{\mathrm{o} \text {-acidic }}$ on the basis of the enthalpies of immersion $\Delta_{\mathrm{i}} \mathrm{H}\left(\mathrm{C}_{6} \mathrm{H}_{6}\right)$ and $\Delta_{\mathrm{i}} \mathrm{H}\left(\mathrm{H}_{2} \mathrm{O}\right)$, which are also mass-related properties. This approach is independent of surface-related properties recently considered by others authors [12,13]. Moreover, with the help of Eq. (5), $\Delta_{\mathrm{i}} \mathrm{H}\left(\mathrm{H}_{2} \mathrm{O}\right)$ provides a good estimate of the total oxygen content of the surface. This, in turn, allows an estimate for the decrease of $\mathrm{C}$ with the current density, j, given by Eq. (4). The relevant parameters may change if other aqueous electrolytes (e.g. $\mathrm{KOH}$ ) are used.

(c) In the case of the aprotic electrolyte $\left(\mathrm{C}_{2} \mathrm{H}_{5}\right)_{4} \mathrm{NBF}_{4}$ in acetonitrile, where the influence of surface oxygen is small, the gravimetric capacitance $\mathrm{C}_{\mathrm{o} \text {-aprotic }}$ can be estimated from $\Delta_{\mathrm{i}} \mathrm{H}\left(\mathrm{C}_{6} \mathrm{H}_{6}\right)$ alone, as given by Eq. (8). However, for carbons with a substantial fraction of micropores below $0.7 \mathrm{~nm}$, this equation overrates $\mathrm{C}_{\mathrm{o} \text {-aprotic }}$ and more reliable information is provided by the enthalpy of immersion into carbon tetrachloride, $\Delta_{\mathrm{i}} \mathrm{H}\left(\mathrm{CCl}_{4}\right)$ and Eq. (10).

(d) The same approach can be applied to aprotic ions with different critical dimensions, by using an appropriate liquid probe. As shown elsewhere [1-3], chemically inert liquids with molecular dimensions 
up to $1.5 \mathrm{~nm}$ are available for this type of work in immersion calorimetry.

(e) Finally, one may also expect that the combination of both calorimetric and electrochemical techniques can provide a new insight in the EDLC characteristics of more complex systems, for example new types of carbons.

\section{References}

1. Bansal RC, Donnet JB, Stoeckli F. Active Carbon. New York: Marcel Dekker; 1988. p 1-26, 119-62.

2. Stoeckli F. In: Patrick J, editor. Porosity in carbons-characterization and applications. London: Arnold; 1995. p. 67-97.

3. Stoeckli F, Centeno TA. On the characterization of microporous carbons by immersion calorimetry alone. Carbon 1997; 35(8):1097-1100.

4. Stoeckli F, Centeno TA. On the determination of surface areas in activated carbons. Carbon 2005; 43(6): 1184-90.

5. Kaneko K, Ishii C, Ruike M, Kuwabara H. Origin of superhigh surface area and microcrystalline graphitic structures of activated carbons. Carbon 1992; 30(7): 1075-88.

6. Stoeckli F, Lavanchy A. The adsorption of water by active carbons. Carbon 2000; 38(3): 475-7. 
7. Centeno TA, Stoeckli F. The role of textural characteristics and oxygencontaining surface groups in the supercapacitor performances of activated carbons. Electrochimica Acta 2006; 52(2): 560-6.

8. Sevilla M, Álvarez S, Centeno TA, Fuertes AB, Stoeckli F. Performance of templated mesoporous carbons in supercapacitors. Electrochimica Acta 2007; 52(9): 3207-15.

9. Centeno TA, Hahn M, Fernández JA, Kötz R, Stoeckli F. Correlation between capacitances of porous carbons in acidic and aprotic EDLC electrolytes. Electrochem. Commun. 2007; 9(6): 1242-6.

10. Fernández JA, Morishita $T$, Toyoda M, Inagaki M, Stoeckli F, Centeno TA. Performance of mesoporous carbons derived from poly (vinyl alcohol) in electrochemical capacitors. J. Power Sources 2008; 175(1): $675-9$.

11. Lota G, Centeno TA, Frackowiak E, Stoeckli F. Improvement of the structural and chemical properties of a commercial activated carbon for its application in electrochemical capacitors. Electrochim. Acta 2008; 53(5): 2210-6.

12. Chmiola J, Yushin G, Dash R, Gogotsi Y. J. Power Sources 2006; 158 : $765-72$.

13. Chmiola J, Yushin G, Gogotsi Y, Portet C, Simon P, Taberna PL. Science 2006; 313: 1760-3.

14. Hsieh $\mathrm{CT}$, Teng $\mathrm{H}$. Influence of oxygen treatment on electric double-layer capacitance of activated carbon fabrics. Carbon 2002; 40(5): 667-74. 
15. Nian YR, Teng $\mathrm{H}$. Influence of surface oxides on the impedance behavior of carbon-based electrochemical capacitors. J Electroanal. Chem. 2003; 540: 119-27.

16. Bleda-Martínez MJ, Maciá-Agulló JA, Lozano-Castelló D, Morallón, Cazorla-Amorós D, Linares-Solano A. Role of surface chemistry on electric double layer capacitance of carbon materials. Carbon 2005; 43 (13): $2677-84$.

17. Carrasco-Marín F, Mueden A, Centeno TA, Stoeckli F, Moreno-Castilla C. Water adsorption of activated carbons with different degrees of oxidation. J. Chem. Faraday Trans. 1997; 93(12): 2211-5.

18. Ballerini L, Huguenin D, Rebstein P, Stoeckli F. Determination of the total surface area in carbonaceous adsorbents by the selective adsorption of caffeine from water. J. Chim. Phys. 1990; 87: 1709-14.

19. Stoeckli F, López-Ramón MV, Moreno-Castilla C. Adsorption of phenolic compounds from aqueous solutions, by activated carbons, described by the Dubinin-Astakhov equation. Langmuir 2001;17(11): 3301-6.

20. Fernández E, Hugi-Cleary D, López-Ramón MV, Stoeckli F. Adsorption of phenol from dilute and concentrated aqueous solutions by activated carbons. Langmuir 2003;19(23): 9719-23.

21. Centeno TA, Sevilla M, Fuertes AB, Stoeckli F. On the electrical doublelayer capacitance of mesoporous templated carbons. Carbon 2005; 43(14): 3012-15. 
22. Morita M, Watanabe S, Ishikawa M, Tamai H, Yasuda H. Utilization of activated carbon fiber with mesopore structure for electric double layer capacitors. Electrochemistry 2001; 69(6): 462-6.

23. Stoeckli F, Slasli A, Hugi-Cleary D, Guillot A. The characterization of microporosity in carbons with molecular sieve effects. Microp. Mesop. Mater. 2002; 51(3): 197-202.

24. Stoeckli F, Guillot A, Slasli A, Hugi-Cleary D. The comparison of experimental and calculated pore size distributions of activated carbons. Carbon 2002; 40(3): 383-8.

25. Stoeckli F, Guillot A, Hugi-Cleary D, Slasli AM. Pore size distributions of active carbons assessed by different techniques. Carbon 2000;38(6): 938-41.

26. López-Ramón MV, Stoeckli F, Moreno-Castilla C, Carrasco-Marín F. On the characterization of acidic and basic surface sites on carbons by various techniques. Carbon 1999; 37(8): 1215-21.

27. Figueiredo JL, Pereira MFR, Freitas MMA, Orfao JJM. Modification of the surface chemistry of activated carbons. Carbon 1999; 37(11): 137989.

28. Centeno TA, Stoeckli F. Applications of immersion calorimetry in Dubinin's theory and in electrochemistry, In: Mota JP, Lyubchik S, editors. Berlin: Springer; 2007. p. 9-18.

29. Centeno TA, Stoeckli F. In: Gupta V, editor. Recent Advances in Supercapacitors. Kerala: Transworld Research Network; 2006, p. 57-77. 
Fig. 1. Correlation between calculated and experimental capacitances $\mathrm{C}_{\text {o-acidic }}$ for 89 carbons, using Eq. (6).

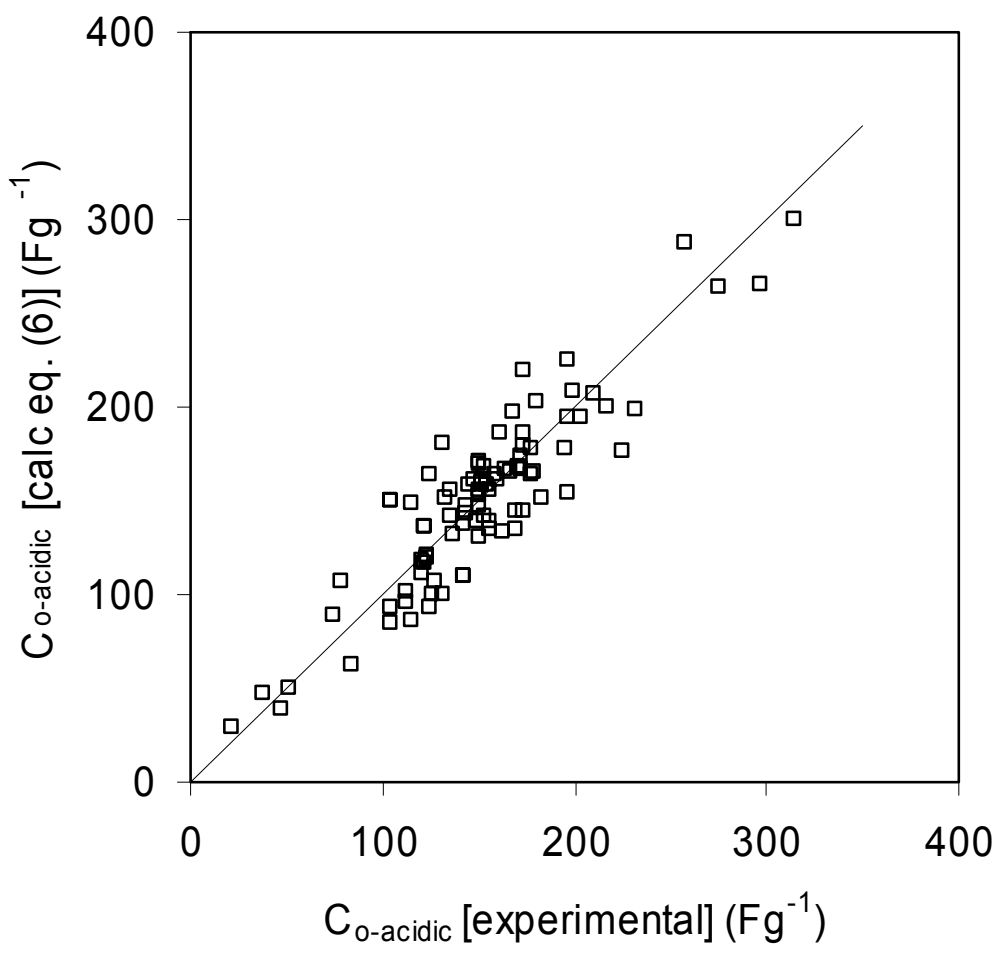


Fig. 2. Correlation between $\mathrm{C}_{\text {o-aprotic }}$ and $\Delta_{\mathrm{i}} \mathrm{H}\left(\mathrm{C}_{6} \mathrm{H}_{6}\right)$ for carbons with a majority of pores above $0.75-0.80 \mathrm{~nm}(\square)$ and carbons containing a significant fraction of its porosity below $0.7-0.75 \mathrm{~nm}(\mathbf{n}$, see Table 2$)$. The line through the origin corresponds to a linear best fit for the carbons with a majority of pores above 0.75 to $0.80 \mathrm{~nm}$, given by Eq. (8).

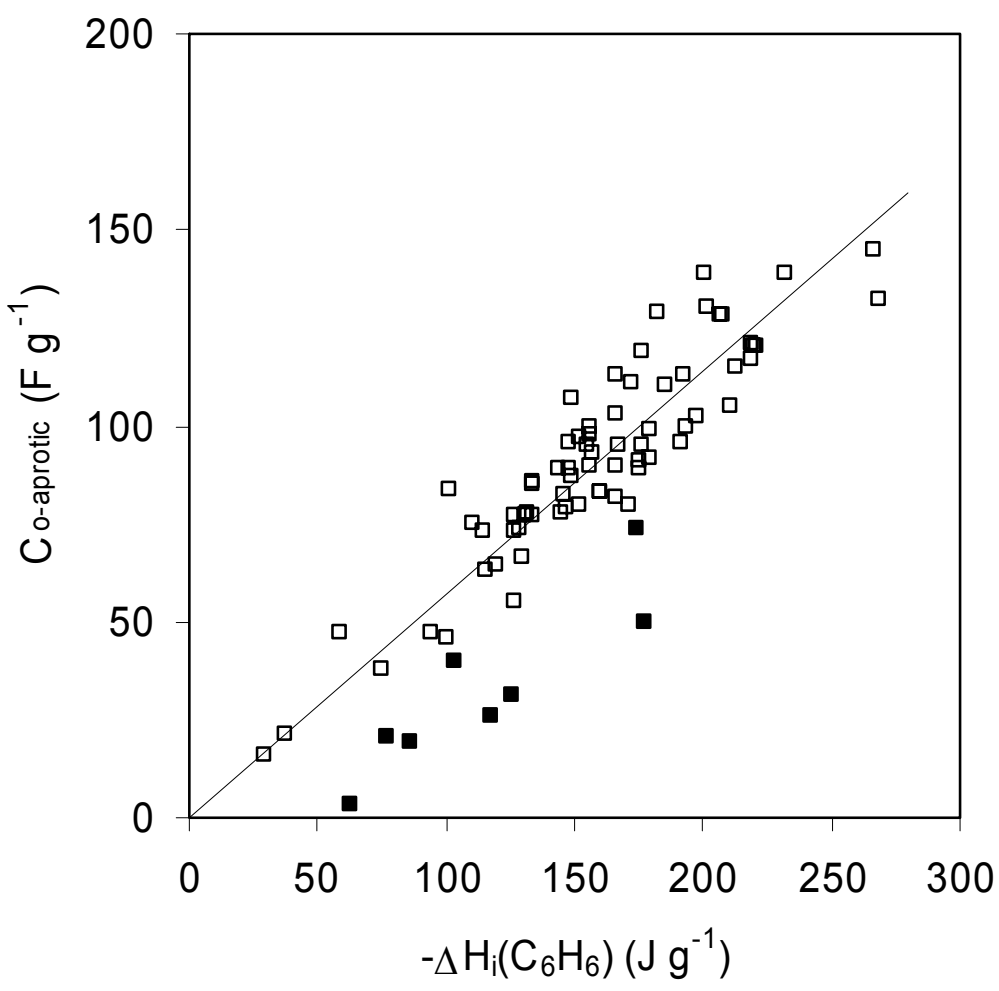


Fig. 3. Correlation between $\mathrm{C}_{\text {o-aprotic }}$ and $\Delta_{\mathrm{i}} \mathrm{H}\left(\mathrm{CCl}_{4}\right)$ for 31 carbons. The line through the origin corresponds to Eq. (10) and the insets give the average pore widths below ( $\square$ ) and above ( $\square) 0.7 \mathrm{~nm}$.

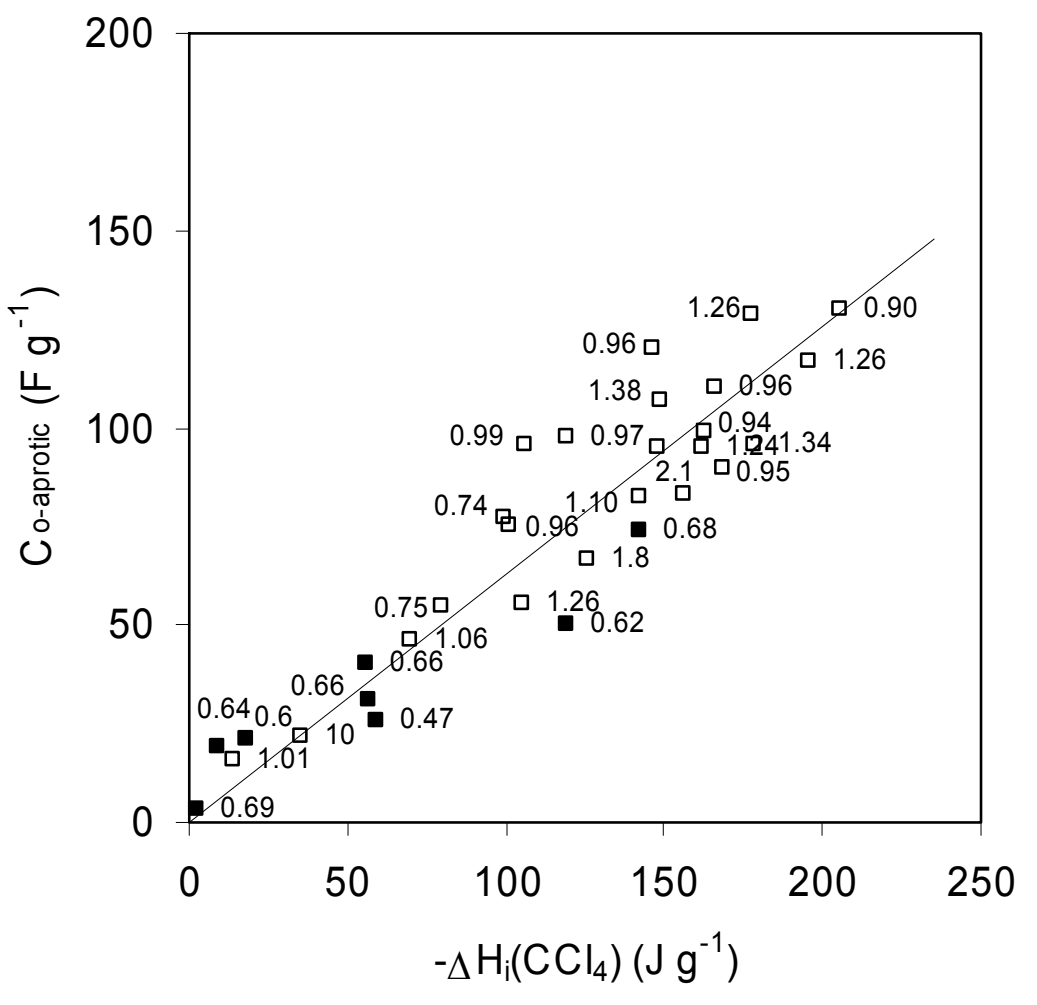


Table 1. General properties of typical porous carbons of different origins. See also $[3,4,6-10,19,26]$

\begin{tabular}{|c|c|c|c|c|c|}
\hline Material type & Carbon & $\underset{\left(m^{2} g^{-1}\right)}{S_{m i}}$ & $\left(\mathrm{~m}^{2} \mathrm{~g}^{-1}\right)$ & $\begin{array}{l}\mathrm{S}_{\text {total }} \\
\left(\mathrm{m}^{2} \mathrm{~g}^{-1}\right)\end{array}$ & $\begin{array}{l}\text { Average pore width } \\
\text { (nm) }\end{array}$ \\
\hline \multirow{5}{*}{ Activated carbon fibers } & Kevlar-50 & 919 & 34 & 953 & 0.74 \\
\hline & ACC-17 & 1333 & Neg. & 1333 & 0.87 \\
\hline & Nomex-50 & 1114 & 9 & 1123 & 0.97 \\
\hline & ACC-23 & 1254 & 5 & 1259 & 1.26 \\
\hline & $K F-1500$ & 910 & 28 & 938 & 1.38 \\
\hline \multirow{12}{*}{ Activated carbon } & CMS & 645 & 20 & 665 & 0.75 \\
\hline & AZ46-0 & 668 & 140 & 808 & 0.96 \\
\hline & No & 659 & 17 & 676 & 1.06 \\
\hline & DCG-5 & 982 & 40 & 1022 & 1.10 \\
\hline & SUPER-30 & 968 & 9 & 977 & 1.24 \\
\hline & BV46-Ox & 651 & 112 & 763 & 1.29 \\
\hline & M-30 & 1050 & 50 & 1100 & 1.33 \\
\hline & AC-35 & 554 & 250 & 804 & 1.35 \\
\hline & UO3 & 570 & 60 & 630 & 1.80 \\
\hline & UO3-ox & 630 & 60 & 690 & 1.80 \\
\hline & $\mathrm{PX}-21$ & 1166 & 104 & 1270 & 2.00 \\
\hline & $\mathrm{N}-125$ & 610 & 157 & 767 & 2.10 \\
\hline Carbon black & XC-72 & 145 & 105 & 250 & 1.01 \\
\hline \multirow{2}{*}{ Carbide-derived carbons } & $\mathrm{SiC}$ & 1289 & 50 & 1339 & 0.90 \\
\hline & $\mathrm{TiC}$ & 1404 & 15 & 1419 & 1.04 \\
\hline \multirow{2}{*}{ emplated mesoporous carbons } & MP91 & Neg. & 1351 & 1351 & 5.3 \\
\hline & MP37 & Neg. & 929 & 929 & 10.5 \\
\hline
\end{tabular}



Table 2. Experimental and calculated limiting capacitances $C_{0 \text {-aprotic }}$ for carbons with small average pore sizes.

For comparison purposes, the values obtained for the non porous high surface area graphite HSAG-300 are also shown.

\begin{tabular}{|c|c|c|c|c|c|c|}
\hline Carbon & $\begin{array}{l}\text { Lo } \\
(\mathrm{nm})\end{array}$ & $\begin{array}{c}-\Delta_{\mathrm{i}} \mathrm{H}\left(\mathrm{CCl}_{4}\right) \\
\left(\mathrm{J} \mathrm{g}^{-1}\right)\end{array}$ & $\begin{array}{c}-\Delta \mathrm{Hi}\left(\mathrm{C}_{6} \mathrm{H}_{6}\right) \\
\left(\mathrm{J} \mathrm{g}^{-1}\right)\end{array}$ & $\begin{array}{c}\mathrm{C}_{\text {o-aprotic }}(\exp ) \\
\left(\mathrm{F} \mathrm{g} \mathrm{g}^{-1}\right)\end{array}$ & $\begin{array}{c}\mathrm{C}_{\text {o-aprotic }} \text { Eq. }(10) \\
\left(\mathrm{F} \mathrm{g}^{-1}\right)\end{array}$ & $\begin{array}{c}\mathrm{C}_{\text {o-aprotic }} \text { Eq. (8) } \\
\left(\mathrm{F} \mathrm{g} \mathrm{g}^{-1}\right)\end{array}$ \\
\hline $\mathrm{T}-0$ & 0.55 & 18.0 & 76.6 & 21 & 11 & 44 \\
\hline AC-11 & 0.62 & 119.5 & 177.8 & 50 & 75 & 102 \\
\hline MC7 & 0.64 & 8.7 & 86.4 & 19 & 5 & 49 \\
\hline PAU & 0.68 & 142.1 & 174.6 & 74 & 89 & 100 \\
\hline MSC-5 & 0.69 & 2.6 & 63.0 & 3 & 2 & 36 \\
\hline HSAG-300 & Graphite & 35.1 & 37.6 & 22 & 22 & 22 \\
\hline
\end{tabular}

